\title{
Designer Cranioplasty at Budget Prices: A Novel Use of 3D Printing Technology
}

\author{
Thirumal Yerragunta ${ }^{1, \odot}$ Reddy Ramanadha Kanala ${ }^{1}$ Vamsi Krishna Yerramneni ${ }^{1}$ \\ Swapnil Kolpakawar ${ }^{1}$ Vasundhara Rangan ${ }^{1}$
}

${ }^{1}$ Department of Neurosurgery, Nizam's Institute of Medical Sciences, Panjagutta, Hyderabad, India

\begin{abstract}
Address for correspondence Ramanadha Reddy Kanala, MCh, Assistant Professor, Department of Neurosurgery, Nizam's Institute of Medical Sciences, Panjagutta, Hyderabad 50008, India, (e-mail: reddyramanadha18@gmail.com).
\end{abstract}

Indian J Neurosurg 2021;10:194-198.

\begin{abstract}
Keywords

- Cranioplasty

- PMMA (polymethylmethacrylate)

- 3D-printed, low-cost

Background Cranioplasty using synthetic materials for restoration of the exact shape of the skull has always remained a challenge until the development of 3D printing technology. However, the high-cost of available 3D printed implants limits their extensive use.

Objectives To study the effectiveness of a low-cost, 3D-printed template for molding the polymethyl methacrylate (PMMA) (bone cement) in order to achieve exact contours of the skull specific to each patient.

Materials and Methods 10 cranioplasties have been performed between July 2018 to December 2019 in a variety of craniotomy defects using bone cement flaps shaped using custom-made molds. The mold was 3D-printed and based on each patient's CT images in digital imaging and communications in medicine (DICOM). Miniplates and screws were used to fix the flap. Postoperatively, clinical and radiological evaluation were done to assess patient satisfaction and accuracy of contour achieved.

Results Patient satisfaction as well as accuracy of contouring, as seen on postoperative CT scans, were excellent. There were no notable complications on follow-up.

Conclusion PMMA cranioplasty flap, contoured using a 3D-printed mold, is a very cost-effective alternative for restoration of skull contour for various craniotomy defects. Polymethyl methacrylate (PMMA) molded to form the exact shape of lost calvarium using $3 \mathrm{D}$ printed plastic templates is a smart and economical solution.
\end{abstract}

\section{Key messages}

- Cranioplasty materials and implant designs are constantly evolving

- Currently available custom-made implants are unaffordable for many Indian patients

- Polymethyl methacrylate (PMMA) molded to form the exact shape of lost calvarium using 3D printed plastic templates is a smart and economical solution

\section{Introduction}

Cranioplasty is a commonly performed procedure in neurosurgical practice. Frequently, there is loss of autologous bone flap to infection, comminuted fracture, resorption over time, tumor invasion, or unplanned excess drilling. Such situations require calvarial defect coverage with flaps made of synthetic material. While each synthetic material has its advantages and disadvantages with respect to their use in cranioplasty, published online March 9, 2021
DOI https://doi.org/

10.1055/s-0040-1716995

ISSN 2277-954X. (c) 2021. Neurological Surgeons' Society of India.

This is an open access article published by Thieme under the terms of the Creative Commons Attribution-NonDerivative-NonCommercial-License, permitting copying and reproduction so long as the original work is given appropriate credit. Contents may not be used for commercial purposes, or adapted, remixed, transformed or built upon. (https://creativecommons.org/licenses/by-nc-nd/4.0/).

Thieme Medical and Scientific Publishers Pvt. Ltd. A-12, 2nd Floor, Sector 2, Noida-201301 UP, India 
the biggest challenge remains contouring those synthetic materials to achieve the original shape of the patient's lost skull flap at an affordable price. Although various methods have been described in literature, their wide use remains difficult in a hospital such as ours due to technical complexity and high cost. ${ }^{1}$

In this context, the advent of 3D printing technology into medicine has offered ingenious solutions. ${ }^{2}$ However, 3D printed synthetic material bone flaps are too expensive, thereby limiting their wider application. ${ }^{3}$ Most commercially available 3D printed calvarial implants are made using PEEK (polyether ether ketone) or titanium. Using PMMA as the material for construction cuts the cost of the implant down significantly. PMMA (bone cement) is a versatile material for molding, although it cannot be directly used for 3D printing, as it is available as components that harden quickly when mixed. To overcome this challenge, the authors in this study used individualized inexpensive 3D printed plastic molds to shape the bone cement (PMMA) into flaps that conform to the exact size and shape of each patient's calvarial defect.

The aim is to study the effectiveness of a low-cost, 3D-printed template for molding PMMA (bone cement) in order to create individualized implants for cranioplasty.

\section{Materials and Methods}

All patients admitted at the Nizam's Institute of Medical Sciences (NIMS) requiring synthetic flap cover for calvarial defects were included in the study. Ten patients have undergone this method of cranioplasty after May 2018.

\section{Technique}

Each patient underwent CT head with thin axial slices. The digital imaging and communications in medicine (DICOM) images were transferred to the software platform (3D SLICER). Using this software, reconstruction of those axial images into a 3D skull image with evident bone defect was done. The skull defect was reshaped using a mirror image of the normal side. The software has algorithms to make a 3D image of the flap, conforming to the required contours and the thickness and matching with various regions of the calvarial defect. The flap images were transferred to a 3D printer in "STL" format. Two parts, one conforming to innertable (drag) and another conforming to outer table (cope), of the defect were printed. Acrylonitrile butadiene styrene (ABS) plastic is used for making the molds. The parts of the mold were gas sterilized. During surgery, once the craniotomy defect is defined after dissection, the two parts of the mold were lined with sterile plastic sheets to avoid sticking of cement onto the mold. The bone cement (PMMA) is then molded into a flap by placing it between the two templates to achieve required thickness and contour. The flap is taken before complete hardening of the cement, and the size and contour checked by placing it on the exposed dural surface. Any extra material at the edges is trimmed off at this time, because once the bone cement is fully hardened, it is difficult to cut through. This molded cement flap is fixed to the surrounding skull using titanium plates and screws. The technique is described in a stepwise manner for the bifrontal craniotomy defect depicted in -Fig. 1.

In bifrontal craniectomy cases, we do not have the advantage of making a mirror image of the normal side. In this scenario, we use reconstructed images based on the precraniotomy CT of head when available. When a normal preop CT image is unavailable, the flap is created based on curvature analysis of the skull defect.

Clinical and radiological evaluation were done in the immediate postoperative period as well as on follow-up. Patient satisfaction with the cosmetic outcome was graded as Excellent, Good, Fair or Poor. Cranial contour was studied on the postcranioplasty CT scan. Contouring was considered Excellent when flap was correctly aligned (within $1 \mathrm{~mm}$ ) with defect, Accurate when flap dislocation was at least equal to the thickness of the surrounding skull, and Inaccurate when flap dislocation was more than the thickness of the skull.

\section{Results}

A total of 10 cases underwent cranioplasty using such molded PMMA implants. Age, gender, primary diagnosis leading to craniotomy, location of craniotomy defect (frontotemporoparietal [FTP] defect, bifrontal or small defects), reason for bone flap loss, patient satisfaction, radiological outcome, and postoperative complications of each patient have been depicted in - Table 1. In 8 of the 10 cases, cranioplasty was done within 3 to 6 months of the first surgery. Of the other two, one case was a patient who presented with an exposed implant at the floor of a nonhealing scalp ulcer, which developed after a titanium mesh cranioplasty done at another hospital about 1 year ago. The mesh was removed and cranioplasty was done using our technique with excellent results. Another patient was a case of fibrous dysplasia of $4 \times 4 \mathrm{~cm}$ at the center of the forehead. The planned surgical defect was marked, and the mold prepared preoperatively in this case. Excision of involved bone and PMMA cranioplasty was done in the same sitting. This did not lead to a good cosmetic outcome and 1 month following surgery, the patient developed cerebrospinal fluid (CSF) rhinorrhea. Reexploration with frontal sinus packing and revision cranioplasty with titanium mesh was then performed. Hence, 9 out of 10 cases were managed with PMMA implants with good to

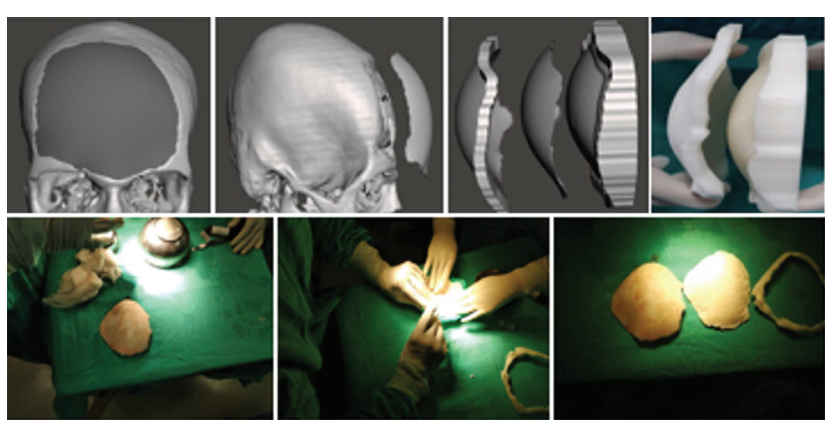

Fig. 1 Reconstruction of axial CT images of 3D skull with defect, making of mold, and making of bone flap with PMMA using mold. PMMA, polymethyl methacrylate. 
Table 1 Patient demographic details and results

\begin{tabular}{|c|c|c|c|c|c|c|c|}
\hline $\begin{array}{l}\text { S. } \\
\text { No. }\end{array}$ & $\begin{array}{l}\text { Age/ } \\
\text { sex }\end{array}$ & Diagnosis & $\begin{array}{l}\text { Site and type } \\
\text { of craniotomy } \\
\text { defect }\end{array}$ & $\begin{array}{l}\text { Reason for } \\
\text { bone flap loss }\end{array}$ & Patient satisfaction & $\begin{array}{l}\text { Postop } \\
\text { complications }\end{array}$ & $\begin{array}{l}\text { Comparison } \\
\text { of pre and } \\
\text { post op CT }\end{array}$ \\
\hline 1 & $25 / M$ & RTA with $\mathrm{HI}$ & $\begin{array}{l}\text { Right FTP } \\
(14 \times 12 \mathrm{~cm})\end{array}$ & $\begin{array}{l}\text { Infection } \\
\text { (abdominal } \\
\text { parietes) }\end{array}$ & Excellent & $\mathrm{Nil}$ & Excellent \\
\hline 2 & $17 / M$ & RTA with $\mathrm{HI}$ & $\begin{array}{l}\text { Bifrontal } \\
(12 \times 10 \mathrm{~cm})\end{array}$ & $\begin{array}{l}\text { Comminuted } \\
\text { fracture }\end{array}$ & Excellent & $\mathrm{Nil}$ & Excellent \\
\hline 3 & $45 / M$ & RTA with $\mathrm{HI}$ & $\begin{array}{l}\text { Left FTP } \\
(14 \times 12 \mathrm{~cm}) \\
\text { (with mesh } \\
\text { exposure) }\end{array}$ & $\begin{array}{l}\text { Mesh } \\
\text { cranioplasty } \\
\text { done with } \\
\text { current non- } \\
\text { healing scalp } \\
\text { ulcer }\end{array}$ & Good & $\mathrm{Nil}$ & Excellent \\
\hline 4 & $14 / \mathrm{M}$ & $\begin{array}{l}\text { Left Insular } \\
\text { glioma }\end{array}$ & $\begin{array}{l}\text { Left FTP } \\
(10 \times 8 \mathrm{~cm})\end{array}$ & $\begin{array}{l}\text { Infection } \\
\text { (abdominal } \\
\text { parietes) }\end{array}$ & Good & $\mathrm{Nil}$ & $\begin{array}{l}\text { Accurate } \\
\text { After } 1 \text { year, } \\
\text { bone flap } \\
\text { was sunken } \\
\text { and hence } \\
\text { revision sur- } \\
\text { gery done }\end{array}$ \\
\hline 5 & $25 / M$ & $\begin{array}{l}\text { Fall of object } \\
\text { overhead with } \\
\text { depressed } \\
\text { comminuted } \\
\text { fracture }\end{array}$ & $\begin{array}{l}\text { Vertex } \\
(5 \times 5 \mathrm{~cm})\end{array}$ & $\begin{array}{l}\text { Comminuted } \\
\text { fracture }\end{array}$ & Excellent & $\mathrm{Nil}$ & Excellent \\
\hline 6. & $32 / \mathrm{M}$ & $\begin{array}{l}\text { Occipital } \\
\text { craniotomy for } \\
\text { PCA aneurysm } \\
\text { clipping }\end{array}$ & $\begin{array}{l}\text { Occipital } \\
(10 \times 5 \mathrm{~cm})\end{array}$ & $\begin{array}{l}\text { Osteomyelitis } \\
\text { of bone flap in } \\
\text { situ }\end{array}$ & Excellent & $\mathrm{Nil}$ & Excellent \\
\hline 7. & $40 / M$ & $\begin{array}{l}\text { RTA with frontal } \\
\text { bone depressed } \\
\text { fracture with } \\
\text { underlying } \\
\text { contusion }\end{array}$ & $\begin{array}{l}\text { Bifrontal } \\
(12 \times 10 \mathrm{~cm})\end{array}$ & $\begin{array}{l}\text { Comminuted } \\
\text { bone fracture }\end{array}$ & Excellent & $\mathrm{Nil}$ & Excellent \\
\hline 8. & $50 / F$ & $\begin{array}{l}\text { Fibrous dysplasia } \\
\text { of frontal bone }\end{array}$ & $\begin{array}{l}\text { Frontal } \\
(4 \times 4 \mathrm{~cm})\end{array}$ & Dysplastic bone & Fair & $\begin{array}{l}\text { Replaced with } \\
\text { mesh later due to } \\
\text { complications }\end{array}$ & Accurate \\
\hline 9. & $28 / \mathrm{M}$ & RTA with $\mathrm{HI}$ & $\begin{array}{l}\text { FTP } \\
(10 \times 12 \mathrm{~cm})\end{array}$ & $\begin{array}{l}\text { Infection } \\
\text { (abdominal } \\
\text { parietes) }\end{array}$ & Excellent & $\mathrm{Nil}$ & Excellent \\
\hline 10. & $50 / F$ & $\begin{array}{l}\text { Right MCA } \\
\text { infarct }\end{array}$ & $\begin{array}{l}\text { FTP } \\
(12 \times 10 \mathrm{~cm})\end{array}$ & $\begin{array}{l}\text { Infection } \\
\text { (abdominal } \\
\text { parietes) }\end{array}$ & Excellent & $\mathrm{Nil}$ & Excellent \\
\hline
\end{tabular}

Abbreviations: FTP, frontotemporoparietal; HI, head injury; PCA, posterior cerebral artery; RTA, road traffic accident.

excellent results. No long-term complications or infections were noted in our patients. An illustrative case of bifrontal cranioplasty is presented in - Fig. 2.

The current price of a standard 3D-printed custom-made titanium mesh implant is upward of 1,00,000 INR (1346 USD) for a standard hemicraniectomy defect. Custom-made PEEK implants are even more expensive (double or more in cost compared to the titanium ones). The cost of titanium plates was minimal and use of screws was common to all implants. In our study, getting a mold made costed us around 15000 INR (200 USD), and the cost of bone cement was 8000 INR (107 USD) for a large FTP defect. This was found to be the cheapest option available for a custom-made contoured

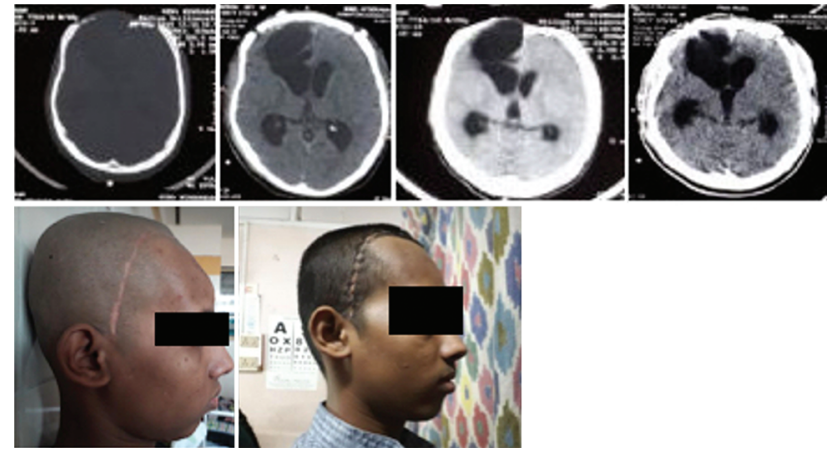

Fig. 2 Comparison of preoperative and postoperative CT head with bifrontal craniotomy defect, and patient face photograph before and after surgery. 
cranioplasty implant. The cost of printing of the mold can be substantially reduced or made negligible with the availability of 3D printers and expertise. The cosmetic outcome with this method was far better than noncustom-made titanium mesh (while even being cheaper) or PMMA implants.

\section{Discussion}

The history of cranioplasty is an interesting one, ${ }^{4-8}$ in which a multitude of materials ranging from the logical (autologous split thickness calvarium, ${ }^{9}$ allografts, and even xenografts ${ }^{7}$ ) to the bizarre (coconut shells ${ }^{8}$ ) have been tried to replace lost calvarium. Currently, PMMA, titanium and, most recently, PEEK are being used with varying degrees of success. Cranioplasty, being a frequent neurosurgical procedure, has been in need of a simple and cost-effective solution to replace a lost bone flap.

Since it is not clear what the ideal implant is, implants are often chosen based on local availability, affordability, and personal preference. Autografts require more extensive surgery for their harvest. PMMA is a widely used material and can be arguably considered the material of choice due to its good biocompatibility, low radio-opacity, strong resistance to functional stress, good osseointegration with patient anatomy, easy handling, and low-cost.10,11 Its few limitations include the exothermic nature of the hardening reaction and rare allergic reactions. ${ }^{12,13}$ The widely used titanium, although highly biocompatible and MRI compatible, leads to a significant artifact on future imaging. The challenge with any graft material is the achievement of the exact shape and size required to fill in the bone defect. Traditionally, PMMA for cranioplasty has been shaped freehand. This method has led to widely varying cosmetic outcomes, with highly unsatisfactory results occurring often. With the advent of 3D printing, this problem appears to be easily solved. Ceramics, hydroxyapatite, PEEK, carbon fiber-reinforced PEEK (CFRP), and titanium have all been successfully remodeled using this technology. ${ }^{14-16}$ In spite of technological advances and custom-made PEEK implants boasting a wide range of advantages, they remain too expensive for wide use in a relatively low socioeconomic setting and almost uniformly prohibitively expensive in our setup. While the affordable and versatile bone cement could not be directly 3D printed, the authors decided to print the templates of the inner and outer tables of the missing calvarium to mold the PMMA. Fiaschi et $\mathrm{al}^{2}$ have already described a similar technique in pediatric patients by using a prefabricated PMMA implant. Marbacher ${ }^{1}$ et al described the technique of contouring the PMMA flap using the pathological bone as a template. This technique, although simple, has been found by the authors to have limited application, that is, in cases where contour of the involved bone is intact. Besides, the resulting implant here is also slightly larger or smaller than the original bone.

With the wide availability of technical support for 3D printing, the technique described in this paper has the advantage of ease of performance, accurate contour, as well as coverage of even large defects at a fraction of the cost of other custom-made options. Limitations include minor imperfection at the edges of the implant, which may be corrected before complete hardening of the material. The unavailability of an image to model the implant after, especially in the case of a bifrontal defect or a bilateral FTP defect without any prior intact skull imaging, where even a mirror image approximation is not an option, remains a challenge in all image-based customizations. The current technique like other all 3D technologies need to evolve further in order to provide an accurate shape that perfectly resembles the autologous flap. In cases where bone loss is anticipated in an elective setting (such as in bony involvement by tumors), the defect can be planned on preop imaging, and a suitable mold printed beforehand for intraoperative use. All things considered, for small defects, a titanium mesh would be the simplest solution in the opinion of the authors.

The future of cranioplasty appears to be the integration of computerized design of biodegradable scaffold (polycaprolactone) and tissue engineering. ${ }^{17}$

\section{Conclusions}

Bone loss and the need for external implants for cranioplasty is a routine neurosurgical problem. PMMA has proven to be a valuable and cost-effective material for this purpose. A 3D-printed plastic mold is practically a homemade solution for contouring PMMA. With comparable cosmetic results, the authors, with such molded bone cement implants, present the most economically effective method available today.

\section{Conflict of Interest}

None declared.

\section{References}

1 Marbacher S, Andereggen L, Erhardt S, et al. Intraoperative template-molded bone flap reconstruction for patient-specific cranioplasty. Neurosurg Rev 2012;35(4):527-535, discussion 535

2 Fiaschi P, Pavanello M, Imperato A, et al. Surgical results of cranioplasty with a polymethylmethacrylate customized cranial implant in pediatric patients: a single-center experience. J Neurosurg Pediatr 2016;17(6):705-710

3 Luo J, Liu B, Xie Z, et al. Comparison of manually shaped and computer-shaped titanium mesh for repairing large frontotemporoparietal skull defects after traumatic brain injury. Neurosurg Focus 2012;33(1):E13

4 Courville CB. Cranioplasty in prehistoric times. Bull Los Angel Neuro Soc 1959;24(1):1-8

5 Stula, D. Cranioplasty. Berlin: Springer; 1985

6 Sanan A, Haines SJ. Repairing holes in the head: a history of cranioplasty. Neurosurgery 1997;40(3):588-603

7 Gladstone HB, McDermott MW, Cooke DD. Implants for cranioplasty. Otolaryngol Clin North Am 1995;28(2):381-400

8 Ellis. W. Polynesian Researches Vol. III. London: Fisher, Son \& Jackson; 1836: 34

9 Vanaclocha V, Sáiz-Sapena N, García-Casasola C, De Alava E. Cranioplasty with autogenous autoclaved calvarial bone flap in the cases of tumoural invasion. Acta Neurochir (Wien) 1997;139(10):970-976

10 Moreira-Gonzalez A, Jackson IT, Miyawaki T, Barakat K, DiNick V. Clinical outcome in cranioplasty: critical review in long-term follow-up. J Craniofac Surg 2003;14(2):144-153 
11 Marchac D, Greensmith A. Long-term experience with methylmethacrylate cranioplasty in craniofacial surgery. J Plast Reconstr Aesthet Surg 2008;61(7):744-752, discussion 753

12 Kirby BS, Doyle A, Gilula LA. Acute bronchospasm due to exposure to polymethylmethacrylate vapors during percutaneous vertebroplasty. AJR Am J Roentgenol 2003;180(2):543-544

13 Li C, Mason J, Yakimicki D. Thermal characterization of PMMAbased bone cement curing. J Mater Sci Mater Med 2004; 15(1):85-89

14 Wolford LM, Cottrell DA, Henry CH. Temporomandibular joint reconstruction of the complex patient with the Techmedica custom-made total joint prosthesis.J Oral Maxillofac Surg 1994; 52(1):2-10, discussion 11
15 Rotaru H, Baciut M, Stan H, et al. Silicone rubber mould cast polyethylmethacrylate-hydroxyapatite plate used for repairing a large skull defect. J Craniomaxillofac Surg 2006; 34(4):242-246

16 Blake GB, MacFarlane MR, Hinton JW. Titanium in reconstructive surgery of the skull and face. Br J Plast Surg 1990; 43(5):528-535

17 Chim H, Schantz J-T. New frontiers in calvarial reconstruction: integrating computer-assisted design and tissue engineering in cranioplasty. Plast Reconstr Surg 2005;116(6):1726-1741 